excellence depriving other areas of individuals inspired to create change. In parts of the country some of these problems have been assisted by the stimulus of the Initlative, but they need to be further addressed if community forms of care are to succeed nationally.

The amount of money involved, totalling £3 million, is relatively small compared to the UK mental health budget. But the aims of the Initlative are to be applauded and the results of the evaluation of the different projects should make a significant contribution to nationwide clinical practice. This is to be welcomed as a research initiattve to directly inform clinical practice and assist in the implementation of effective local community mental health services.

Sara Davies, Senior Registrar, The Maudsley Hospital, Denmark Hill, London SE5 8AZ

\title{
The currency of emotion
}

\section{Larry Culliford}

Currency implies flow and, secondarlly, value. Money flows; it has no purpose otherwise and money, of course, denotes a form of worth.

The emotions are fluid, and also help to ascertain value.

Who knows where anxiety, fear, ends and anger takes its place? Where does anger end and bewilderment begin? How close is bewilderment to doubt, doubt to shame and shame to guilt? And do they not all-in the general flow of things-give rise to sorrow?

And again, when loss is accepted and grief fades, when non-anger replaces anger and sadness loses its grip, does not joy appear like the sun? Shame too departs, and all the rest. With acceptance, is there not clarity of mind in place of confusion? Are not esteem and selfworth re-established over shame? Does not guilt give way to a renewed sense of innocence or virtue? May not these inner feelings then be reflected in outer harmony, in love and peace?

Only when damned, when the flow is interrupted, when anger - non-acceptance reigns, is this resolution prevented. Bewllderment, anger, sorrow, fear: these are of value - but only as currency, as part of the flux and flow of feeling. Wherever such a currency is accepted, all may count themselves rich.

Pain, grief, sorrow, lamentation and despair are the ground of tranquillity, joy and wisdom. Try to value suffering, and simply go with the flow.

Larry Culliford, Consultant Psychiatrist, Hove Community Mental Health Centre, Hove BN3 4AG 